\title{
Experimental investigations of injector internal parameters impact on tip wetting using Laser-induced Fluorescence
}

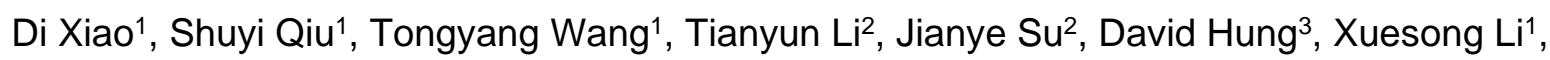 \\ Min $\mathrm{Xu}^{* 1}$ \\ ${ }^{1}$ School of Mechanical Engineering, Shanghai Jiao Tong University, 800 Dongchuan Road, \\ Shanghai, China 200240 \\ 2United Automotive Electronic Systems Co., Ltd.No. 555 Rong Qiao Road, Pudong New \\ Area, Shanghai, China 201206 \\ ${ }^{3}$ University of Michigan-Shanghai Jiao Tong University Joint Institute, Shanghai Jiao Tong \\ University,800 Dongchuan Road, Shanghai, China 200240 \\ *Corresponding author email : mxu@sjtu.edu.cn
}

\begin{abstract}
Fuel film deposited on the injector tip would dramatically cause pool fire, tip deposits and incomplete combustions. Previous research indicated that tip wetting phenomenon had a strong relationship with various operation conditions such as injection pressure, ambient pressure, fuel temperature. Besides, several investigations found that the internal design parameters would affect the tip film generation. However, the effect of internal configurations on tip wetting was not clear, especially combined with typical engine operation conditions, which would provide great guidance to optimize the nozzle design and improve the fuel injection strategy. In this research, Laser-induced Fluorescence method was adopted to investigate the tip wetting process. The influence of in-nozzle configurations was thoroughly discussed using three injectors with different spray hole positions and structures. Three typical operating conditions were also taken into consideration. The film area and thickness were analysed as a function of time. It was found that under sub-cooled and long injection duration, the effect of spray hole position and structure on tip wetting film area and thickness distribution was pretty small, while under flash boiling conditions, the in-nozzle parameters became important. Larger tip wetting films appeared under a special designed spray hole arrangement, which should be taken into consideration to avoid potential deterioration of the combustion and emission performance.
\end{abstract}

\section{Keywords}

Tip wetting, Laser-induced Fluorescence, injector internal structure

\section{Introduction}

PN emission is one of the most significant pollutant emissions of today's internal combustion engines, especially in gasoline direct injection (GDI) engines. Insufficient combustion caused by fuel rich zone in piston wall wetting and injector tip wetting phenomenon are considered as the main source of PN emissions. During injection process, droplet parcels deposit into the injector tip surface creating a liquid phase fuel film, which can't fully evaporate before ignition. High temperature and the lack of oxygen will lead to significant particulate emissions.

Recently, an increased number of researches have focused on the significance of tip wetting phenomenon, and various optical diagnostics means have been used to interpret the process and results of film formation. For instance, Laser-induced Fluorescence method combined with microscopic imaging was applied to evaluate the wetting area and it was found that interference of near nozzle spray and step-hole nozzle outlet were main reasons of tip wetting [1]. The film thickness distribution was obtained using an in-situ calibration method and the tip 
wetting information of a six-hole injector was analysed, finding that the increased injection pressure could decrease the film area and particulate emissions [2]. To clarify the inherent mechanism of tip film formation with internal flow, X-ray phase-contrast technique was also applied and it was found that the needle movement, injection pressure and internal configuration affected the formation of film, while the needle bouncing was dominating [3]. Besides, the mechanism of tip wetting phenomenon was discussed and several related theories were represented including wide plume wetting, vortex droplet wetting, fuel dribble wetting and fuel condensation wetting [4]. The pressure drop caused by needle closure would also result in larger droplets attaching to the tip due to the decreased momentum [5]. Tip wetting may also occur when the exiting liquid interacted with counter bore exit, especially in flash boiling conditions [6].

However, the effect of internal configurations on tip wetting was not fully understood, especially combined with typical engine operation conditions, which would provide great guidance to optimize the nozzle design and improve the fuel injection strategy. In this study, visualization of tip wetting film have been conducted using Laser-induced Fluorescence. Three types of injectors with different internal configurations were tested. The film area and thickness were analysed as a function of time and it was found that a special designed spray hole layout would increase the tip wetting dramatically under flash boiling conditions.

\section{Material and Methods}

The experimental setup in this research was illustrated in Figure 1. The measurements were conducted in a constant volume chamber. The injector was mounted in one side of the chamber and a quartz window was placed in the opposite direction to allow optical observation. For the film measurement, a $10 \mathrm{~Hz}, 266 \mathrm{~nm}$ laser was used as the light source and directed towards the injector tip using reflection mirrors (the energy of every single incoming laser pulse was monitored), and finally excited the fuel, commercial gasoline. Then the fluorescence turned back into an intensified CCD camera equipped with a long distance microscope lens. A high pressure fuel supply system was adopted to provide an injection pressure of $35 \mathrm{MPa}$ with a fluctuation of $0.05 \mathrm{MPa}$. The ambient pressure inside the chamber could be controlled precisely to the desired value with a nitrogen source (99.99\%) and a vacuum pump. In this investigation, the impact of ambient temperature was not in the scope thus it was fixed at $25^{\circ}$ C. The fuel temperature was control by water bath and the relationship between the temperature of injector tip and cooling water was carefully calibrated. Since the dense spray in the front of injector tip would block the light path and have an influence on film imaging, a strong purge flow in the top of chamber was used to carry the spray remains away and the conical-shaped collector in the bottom of chamber could further improve the efficiency. 


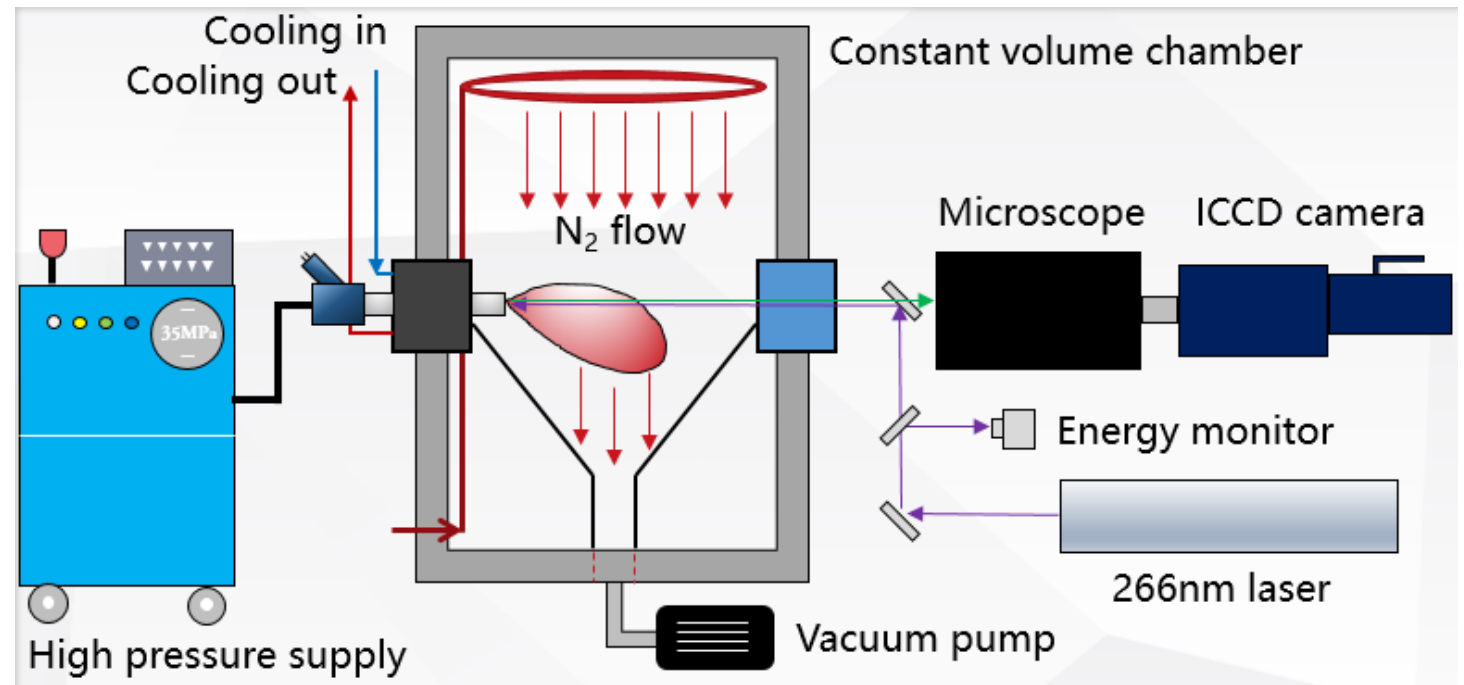

Figure 1. Experimental setup

In this research, a series of GDI two-hole injectors were tested to investigate how the configuration of internal hole would influence the tip wetting. As can be seen in Table 1, two configurations, spray hole position and structure respectively, were paid attention to. Layout \#1 was used as the base injector while Layout \#2 and Layout \#3 represented the different two modified internal scheme shown in table.

Table 1. Tested injectors in the experiment

\begin{tabular}{l|ll}
\hline No. & Injector configuration & Scheme \\
\hline 1 & Spray hole structure & Layout \#1, Layout \#2(Larger spray hole diameter) \\
2 & Spray hole position & Layout \#1, Layout \#3(Smaller pitch circle)
\end{tabular}

The three conditions conducted in the experiment were listed in Table 2. As can be seen, the injection pressure was fixed at 35MPa, while the fuel temperature $\left(T_{f}\right)$, ambient pressure $\left(P_{a m b}\right)$ and injection duration ( $t_{i}$ ) varied. A combination of $25^{\circ} \mathrm{C} \mathrm{T}_{f}$ and $1.0 \mathrm{bar} \mathrm{P}_{\mathrm{amb}}$ represented the sub-cooled fuel injection condition (also as a comparison of the other 2 condition), and the $90^{\circ}$ $\mathrm{C}_{\mathrm{f}}, 0.4$ bar $\mathrm{P}_{\mathrm{amb}}$ represented a flash boiling condition, and finally the injection period was extended to $3.0 \mathrm{~ms}$ to reflect the long injection condition. A time-resolved measurement was conducted and the recording timings of 5, 10, 15, 20,50ms ASOI (after start of injection) were used to record the development of films in the injector tip. Since the laser worked at a fixed frequency of $10 \mathrm{~Hz}$, the results were taken from individual test and not in a sequential manner. To evaluate the cyclic variation, for every timing 15 images were taken.

Table 2. Operation conditions in the experiment

\begin{tabular}{l|lllll}
\hline No. & $\mathrm{P}_{\mathrm{f}}(\mathrm{MPa})$ & $\mathrm{T}_{\mathrm{f}}\left({ }^{\circ} \mathrm{C}\right)$ & $\mathrm{P}_{\mathrm{amb}}(\mathrm{bar})$ & $\mathrm{t}_{\mathrm{i}}(\mathrm{ms})$ & Type \\
\hline 1 & 35 & 25 & 1.0 & 1.5 & Base condition \\
2 & 35 & 90 & 0.4 & 1.5 & Flash boiling condition \\
3 & 35 & 90 & 1.8 & 3.0 & Long injection condition
\end{tabular}

\section{Results and Discussion}

Effect of spray hole structure

In this section, the tip wetting fuel film images from Laser-induced Fluorescence method under different conditions and timings were exhibited in Figure 2. Since the residual fuel inside the 
step hole would emit a pretty strong fluorescence signal which was not the interest of this research, so the two holes were cut off during post-processing period. Three conditions were separated by red lines, and two different spray hole structures with different spray hole diameters presented at the same time. As can be seen, the film had a thicker distribution (represented by LIF signal intensity) at early time but it became thinner as time elapsed. It was worth noticing at higher fuel temperatures, the film intensity weakened quickly due to the strong evaporation effect. It can be seen that under flash boiling condition ( $2^{\text {nd }}$ condition), the tip wetting film was relatively regular and circular, while under other conditions, the films were mostly elliptical or other irregular shapes with a relatively large randomness. That could be explained as under higher ambient pressures, the suppression effect from the environment to the plume was pretty strong, on the contrary, the plume and corresponding film would develop to every direction freely when the ambient pressure was 0.4 bar. Under sub-cooled condition and long injection duration, the film area and intensity were almost the same when changing the spray hole structure, while under flash boiling condition, a larger and thicker film was observed and the influence of spray hole structure was obvious, that is, the larger spray hole diameter contributed to a larger tip wetting film.

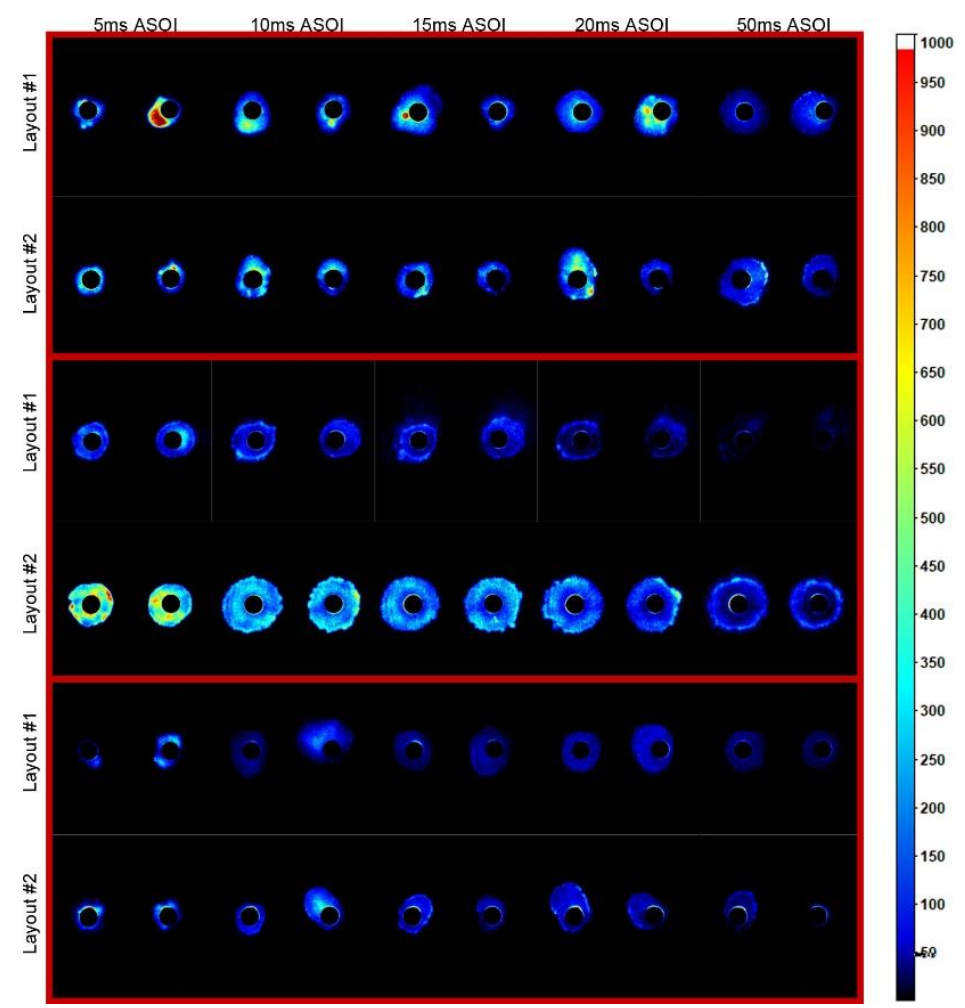

Figure 2. Film development under different conditions when varying spray hole structure

Figure 3 compared the tip wetting film area as a function of time under different conditions when changing the spray hole structure. The results were averaged from 15 individual injections and the error bar represented the standard deviation. Besides, the integrated film intensity was also summarized in Figure 4 to represent the development of thickness. The tendency was generally same with the description mentioned above in Figure 2. For subcooled spray condition, the film area increased all over the time, while for $90^{\circ} \mathrm{C}$ fuel temperature, the film first increased and peaked at 15 or $20 \mathrm{~ms}$ ASOI and then decreased with time as a result of tip drying effect. Under sub-cooled spray condition and long injection condition, the film area was almost same at early injection timings, then a slightly difference 
appeared which could be ignored since their error bars overlapped with each other indicating a randomness existed. And this tiny gap could be attributed to the different evaporation way caused by the uneven film thickness distribution. While for the flash boiling condition, the film area increased dramatically compared to other conditions, which could be explained by the wide plume effect of flash boiling spray and the liquid parcels were more easily impinged into the wall of step hole. Besides, for the smaller pitch circle injector, an obvious increase of film area was observed during all the film development period. The reason may be that the specially modified spray hole structure lead to a smoother inclination angle into the step hole and less bubbles generated, thus the fuel had more possibility to attach the wall.

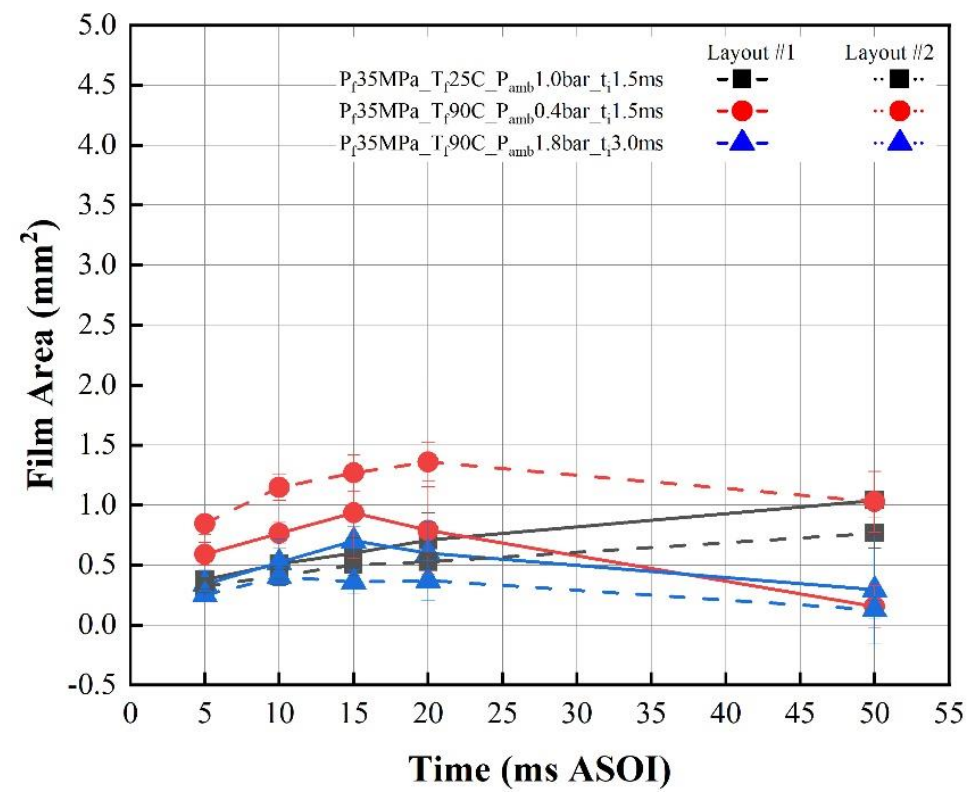

Figure 3. Film area development as a function of time

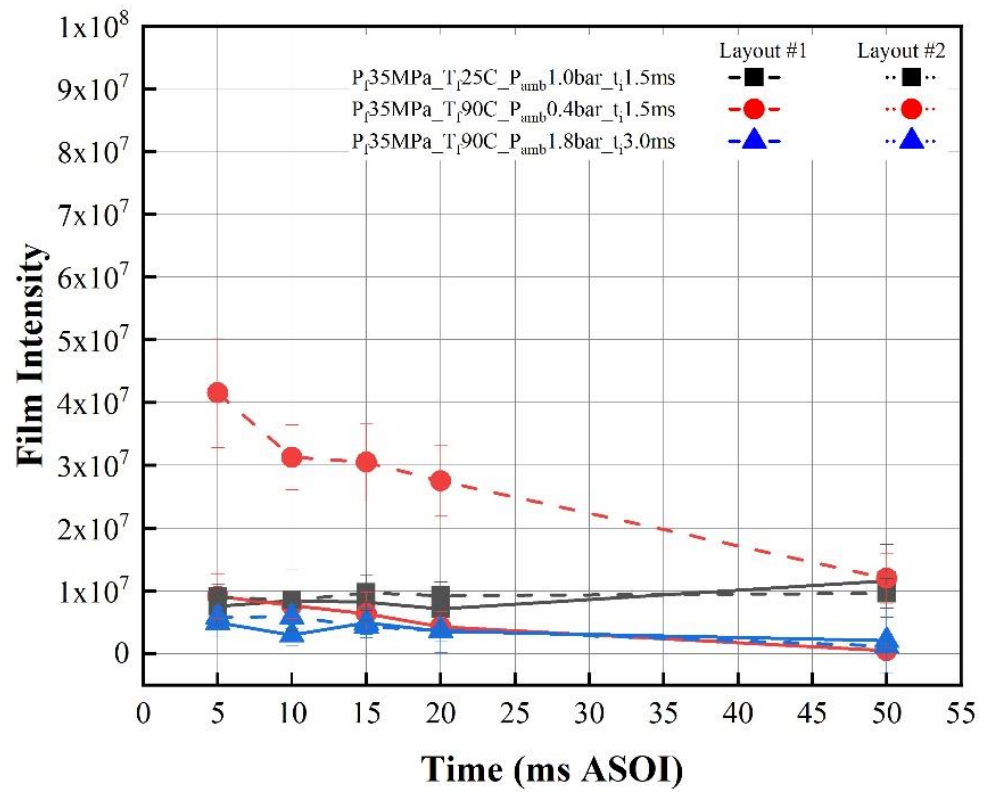

Figure 4. Film intensity development as a function of time

Effect of spray hole position 
Figure 5 compared the film distribution for different spray hole positions. Generally, the development characteristics of films were almost the same with that in Figure 2. However, a thicker film was observed under flash boiling condition when the injector has a smaller pitch circle. Besides, there was a brighter rim around the film, indicating more fuel rushed out of the nozzle and less resistance from the ambient was applied to the film flow above the tip surface.

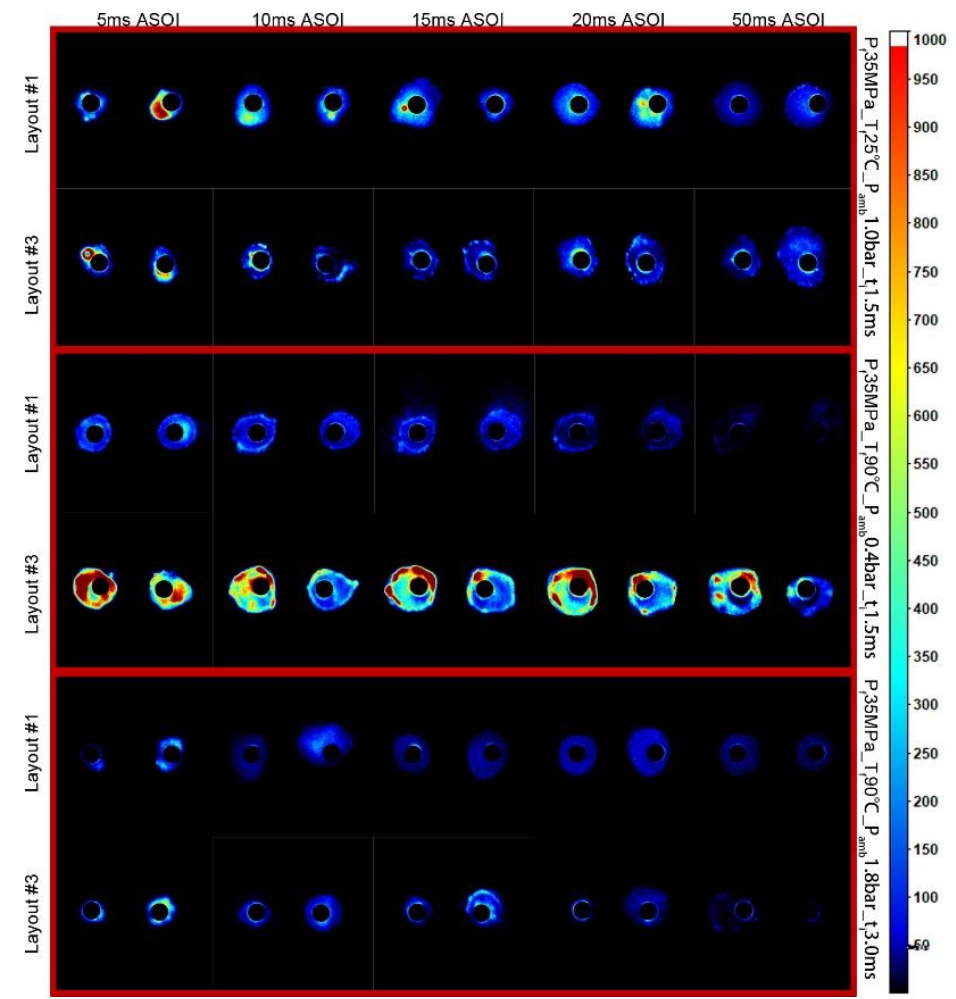

Figure 5. Film development under different conditions when varying spray hole position

To further investigate the characteristics of film when changing the spray hole position, the average area development as a function of time was demonstrated in Figure 6. It could be found that for sub-cooled condition and long injection duration, there was little difference when the spray hole position changed, just the same as the effect of spray hole structure. However, the smaller pitch circle resulted in a dramatically increase of wetting area under flash boiling condition, almost twice larger than the base injector. The film intensity plotted in Figure 7 also revealed a similar tendency. Besides, the smaller pitch circle injector under flash boiling condition represented the thickest film while the other 5 cases had almost the same thickness. A possible explanation about this phenomenon was the enhancement of spray-air entrainment. To be specific, when the two holes were arranged narrower, the distance between two plumes was narrowed, causing a much more complex plume-air interaction under flash boiling condition. More droplets attached into the tip surface during this process, forming a larger and thicker film. To verify the assumption, a high speed imaging method focused on the near field spray was needed in the future. 


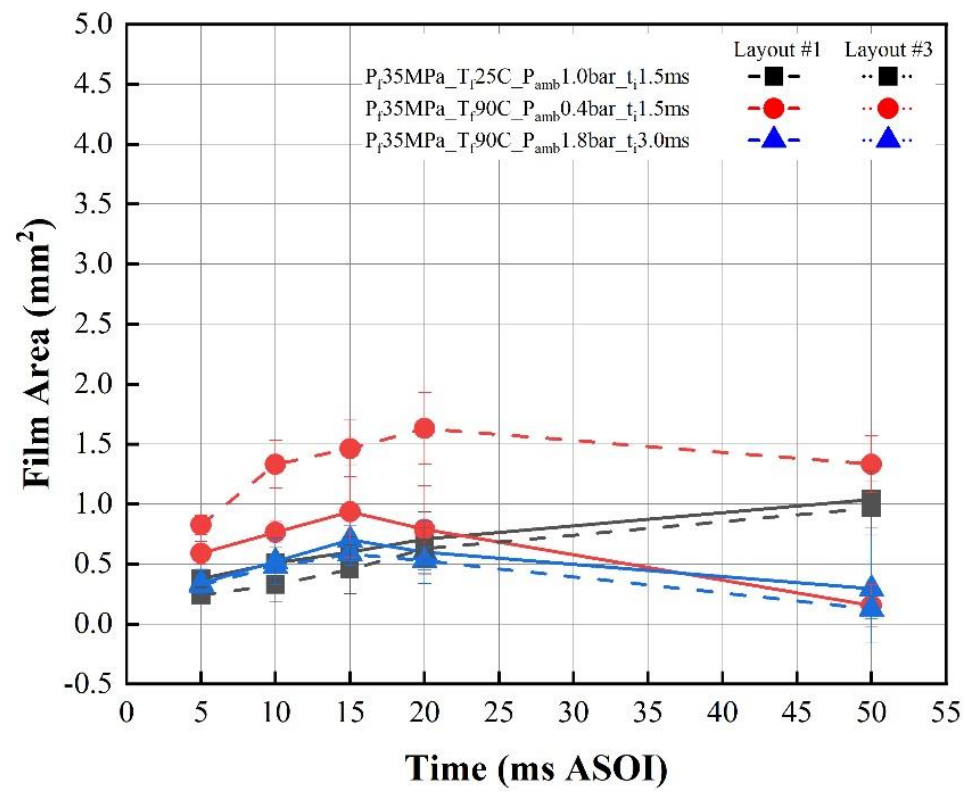

Figure 6. Film area development as a function of time

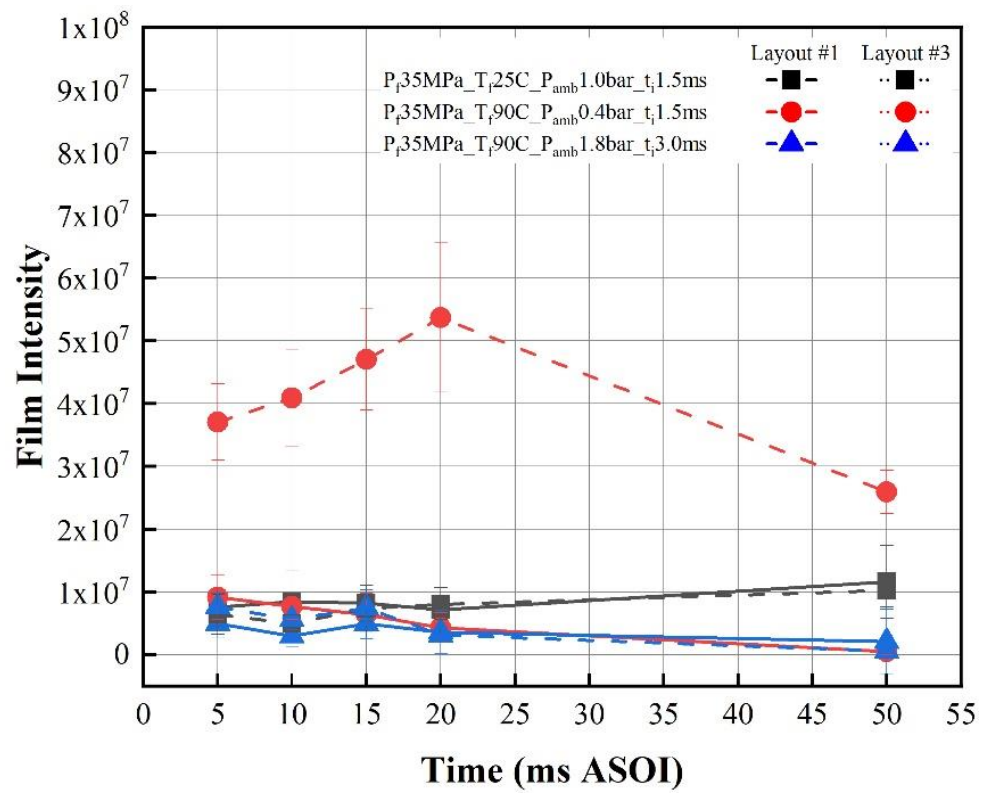

Figure 7. Film intensity development as a function of time

\section{Conclusions}

In this research, Laser-induced Fluorescence method was adopted to investigate the tip wetting process. The influence of in-nozzle configurations was thoroughly discussed using three injectors with different spray hole structures and positions. Three typical operating conditions were also taken into consideration. By analysing the development of film area and thickness as a function of time, it was found that under sub-cooled and long injection duration, the effect of spray hole configurations on tip wetting film area and thickness distribution was pretty small, while under flash boiling conditions, the in-nozzle parameters became important. A specially designed spray hole arrangement in way of larger spray hole diameter and smaller hole diameter would contribute to a larger surface film, which should be taken into consideration to avoid potential deterioration of the combustion and emission performance. 


\section{Acknowledgments}

The authors would like to acknowledge the financial support and technical contribution to this project from United Automotive Electronic Systems Co., Ltd. This research was also sponsored by the National Natural Science Foundation of China (NSFC) under Grants No. E52006140 and No. E51876126. The study was carried out at the National Engineering Laboratory for Automotive Electronic Control Technology of Shanghai Jiao Tong University.

\section{References}

[1] Chansoo Park JJ, Heechang Oh, Juhun Lee, Choongsik Bae. Injector tip wetting evaluation with different nozzle outlet configurations. Proceedings of the 14th triennial international conference on liquid atomization and spray systems, Chicago, IL 2018.

[2] Leick P, Bork B, Geiler JN. Experimental characterization of tip wetting in gasoline DI injectors. Proceedings of the 14th triennial international conference on liquid atomization and spray systems, Chicago, IL. 2018:22-6.

[3] Huang W, Moon S, Wang J, Murayama K, Arima T, Sasaki Y, et al. Nozzle tip wetting in gasoline direct injection injector and its link with nozzle internal flow. International Journal of Engine Research 2020;21(2):340-51.

[4] Medina M, Alzahrani F, Fatouraie M, Wooldridge M, Sick V. Mechanisms of fuel injector tip wetting and tip drying based on experimental measurements of engine-out particulate emissions from gasoline direct-injection engines. International Journal of Engine Research;0(0):1468087420916052.

[5] Peterson K GR. Application of optical diagnostics and simulation to fuel injector tip wetting and soot production. 11th international symposium on combustion diagnostics, Kurhaus of Baden-Baden 2014.

[6] Moulai M, Grover R, Parrish S, Schmidt D. Internal and Near-Nozzle Flow in a Multi-Hole Gasoline Injector Under Flashing and Non-Flashing Conditions. SAE International; 2015. 